\title{
Placement of Shunt VAR Compensator Based on Sensitivity Analysis
}

\author{
Muhammad Nurdin, Fathin Saifur Rahman, Rizky Rahmani, Nanang Hariyanto \\ School of Electrical Engineering and Informatics \\ Institut Teknologi Bandung (ITB), Bandung, Indonesia \\ nurdin@power.ee.itb.ac.id, fathinsr7@gmail.com, rizkyrahmani@gmail.com, \\ nanang.hariyanto@stei.itb.ac.id
}

\begin{abstract}
Voltage stability is a common issue in developing power system. It is mainly affected by reactive power balance in the system. If reactive power is not well planned and managed, there is possibility of occurrence of voltage instability in the system. One solution to prevent voltage instability in the system is by VAR compensation. In this work, new technique to determine the placement of different types of shunt VAR compensators based on sensitivity method is presented. Simultaneous planning of SVC and STATCOM placement is also conducted. Improvement in system stability is achieved using the method.
\end{abstract}

Keywords: Voltage stability, shunt VAR compensator, shunt reactor, shunt capacitor, SVC, STATCOM, voltage index, voltage sensitivity index, angle sensitivity index

\section{Introduction}

Voltage stability is a common issue in developing power system. Voltage stability is the ability of power system to maintain acceptable steady and transient voltage, corresponding to the balance of reactive power [1]. Voltage stability is often distinguished into two categories based on time frame, i.e. transient voltage stability (0-10 seconds) and long term voltage stability ([1] and [2]). [3] shows that if reactive power is not well planned and managed, there is possibility of occurrence of voltage instability in the system. One solution to prevent voltage instability is using VAR compensator.

VAR compensator is a power system device that can absorb or supply reactive power. VAR compensator can be passive VAR compensators or active VAR compensators. Passive VAR compensator includes shunt reactor and shunt capacitor, while the examples of active power compensator that are widely used are static VAR compensator (SVC) and static synchronous compensator (STATCOM). SVC is thyristor-based device, while STATCOM is voltagesourced converter-based devices.

Researches about methods of shunt VAR compensator placement have been conducted by many researchers. [4] divides the methods into three categories: conventional method, heuristic method, and sensitivity-based method. Conventional methods comprise generalized reduced gradient (GRG), Newton's Approach, and Successive Quadratic Programming (SQP) for nonlinear programming. These methods are often trapped by a local optimum solution. Heuristic methods comprise Simulated Annealing (SA), Genetic Algorithms (GA), and Tabu Search (TS). In recent years, these methods have received widespread attention to get global optimum for reactive power planning problem. However, these methods are time consuming. Sensitivity based methods use index, modal, or eigenvalue analysis. In this work, new technique to determine placement of shunt VAR compensators based on sensitivity method is presented. The optimal placement of shunt reactor, shunt capacitor, SVC, and STATCOM were investigated. The simulations use 14-generator model of The SE Australian Power System [5] to verify the method. The method is also tested using Sumatera power system in Indonesia.

\section{Overview on VAR Planning Techniques}

Voltage stability analysis can be divided into static voltage analysis and dynamic voltage

Received: March $24^{\text {th }}, 2014$. Accepted: June $13^{\text {rd }}, 2014$ 
stability analysis. Static voltage analysis concerns two main aspects: determination of how far the system is operating from voltage collapse point and identification of buses or areas that are prone to voltage instability. Several static voltage analysis consist of continuation power flow (CPF), optimal power flow (OPF), and modal analysis. Several dynamic voltage analyses consist of Hopf bifurcation point [6] and time domain analysis.

[7], [8], and [9] use CPF and modal analysis to determine SVC locations, while [10] uses the same method to determine STATCOM location. [6] combines static voltage analysis and dynamic voltage analysis. [11] uses optimal power flow with loss sensitivity index with respect to the control parameters of SVC for optimal placement. [12] uses OPF to minimize fuel cost. However, [11] and [12] ignore voltage stability limits and only consider the economical aspect. Optimal location of FACTS devices in [13] is determined from the viewpoint of increasing the load-ability margin by using CPF and P-V curves. [14] uses P-V curve and time domain analysis to determine the location of SVC. The results from the two study methods are then compared to verify the results. [15] uses modal analysis and time domain simulation to determine the best location for STATCOM. By comparing the results, good correlation between the two techniques is found. Buses with high participation factor in modal analysis are the same with buses that have violations to voltage stability criteria in dynamic analysis. In [16], the result for voltage stability from static and dynamic analysis is compared, which are shown to be consistent in indicating system voltage stability.

\section{Model Development}

One of analysis methods that can be used to develop the model is Newton-Raphson method. By deriving the equations involved in Newton-Raphson load flow analysis, a model to determine optimal placement of shunt VAR compensator based on sensitivity analysis of each bus can be formed.

\section{A. Load Flow Sensitivity}

To develop the model, load flow sensitivity is used based on Newton-Raphson method. Using N-R method, following formula is obtained:

$$
\begin{aligned}
& {\left[\begin{array}{l}
\Delta P \\
\Delta Q
\end{array}\right]=\left[\begin{array}{ll}
\frac{\partial P}{\partial \theta} & \frac{\partial P}{\partial V} \\
\frac{\partial Q}{\partial \theta} & \frac{\partial Q}{\partial V}
\end{array}\right]\left[\begin{array}{c}
\Delta \theta \\
\Delta V
\end{array}\right]} \\
& {\left[\begin{array}{c}
\Delta P \\
\Delta Q
\end{array}\right]=[J]\left[\begin{array}{l}
\Delta \theta \\
\Delta V
\end{array}\right]}
\end{aligned}
$$

where $J$ is Jacobian matrix.

With linearization, the equation can be written as

$$
\left[\begin{array}{ll}
J_{P \theta} & J_{P V} \\
J_{Q \theta} & J_{Q V}
\end{array}\right]\left[\begin{array}{l}
\Delta \theta \\
\Delta V
\end{array}\right]=\left[\begin{array}{l}
\Delta P \\
\Delta Q
\end{array}\right]
$$

To obtain, for example $\partial \mathrm{v} / \partial \mathrm{Q}$, assuming $\Delta \mathrm{P}=0$ :

$$
\begin{aligned}
& J_{P \theta} \Delta \theta+J_{P V} \Delta V=0 \\
& \Delta \theta=-\frac{J_{P V}}{J_{P \theta}} \Delta V \\
& J_{Q \theta} \Delta \theta+J_{Q V} \Delta V=\Delta Q
\end{aligned}
$$


Substituting equation (4) to (5):

$$
\Delta Q=\left(-J_{Q \theta} \frac{J_{P V}}{J_{P \theta}}+J_{Q v}\right) \Delta V
$$

Equation 6 is reduced Jacobian equation. Based on the equation, sensitivity of bus voltage $\mathrm{V}$ to reactive power injection $\mathrm{Q}$ to the bus can be determined. Using the same method, sensitivity of bus angle $\delta$ to active power injection P to the bus can also be determined.

\section{B. Indexes}

To determine the optimal locations for shunt compensator installment, several indexes are used. The sensitivity of buses is used to establish the indexes.

\section{B.1. Voltage Index}

Permissible system voltage is one of constrains that are associated to security of power system operation. The closer bus voltage to its voltage limit, the worse voltage performance becomes. To improve voltage performance in power system, VAR compensator can be used.

Two types of voltage problem that are commonly occurred in power system are undervoltage and overvoltage. Undervoltage problem generally occurs at high loading condition while overvoltage problem occurs at no or low loading condition. The problem can be solved with injection of reactive power using shunt capacitor. On the other hand, overvoltage generally occurs at low loading condition. The problem can be solved with reactive power absorption using shunt reactors.

To obtain significant improvement, VAR compensator should be placed on the buses having severe voltage problems. To assess the level of voltage problem of each bus, voltage index as formulated below is used.

$$
V_{\text {Score } i}=\left\{\begin{array}{l}
1-\frac{V_{\max }-V_{i}}{V_{\max }-1}, V_{i}>1 \\
1-\frac{V_{i}-V_{\min }}{1-V_{\min }}, V_{i} \leq 1
\end{array}\right.
$$

Where

$$
\begin{aligned}
& V_{\max }=\text { maximum permissible system voltage } \\
& V_{\min }=\text { minimum permissible system voltage } \\
& V_{i}=\text { voltage at bus } i
\end{aligned}
$$

Using the index, the severity of voltage problem at each bus can be addressed. When the voltage problem at a bus is more severe, the voltage index at that bus is higher, for both undervoltage and overvoltage problems. When voltage level in a bus violates the permissible value, the index will give the score of more than 1 .

\section{B.2. Voltage Sensitivity Index}

In addition to voltage criteria, voltage sensitivity factor of buses should also be considered in selecting the buses for VAR compensator placement. Voltage sensitivity factor shows the influence of reactive power injection at a bus to voltage changes at that bus. By placing VAR compensator at bus with high voltage sensitivity factor, it is expected that the compensation can be done optimally to provide improvement to overall system voltage performance. Bus with higher voltage sensitivity index needs less amount of VAR to improve voltage at that bus. Furthermore, buses with high voltage sensitivity are located around locus of critical points of V-Q curve. Therefore, placing VAR compensator at those buses will increase voltage stability. 


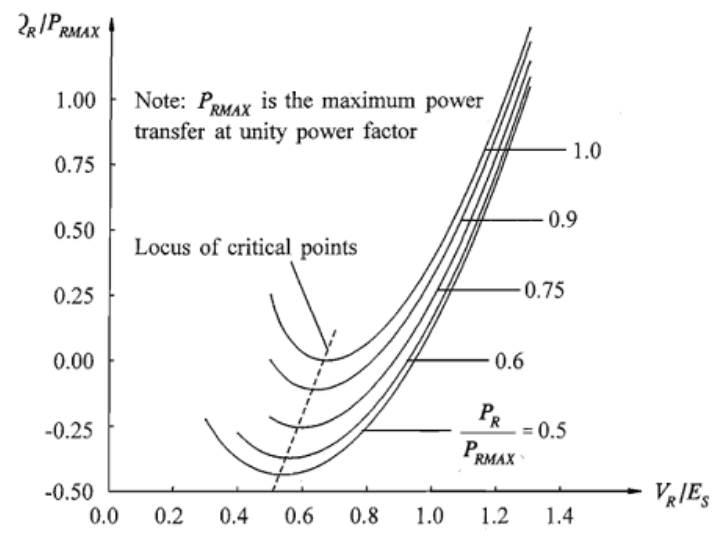

Figure 1. V-Q curve [1]

Every bus in power system has its unique voltage sensitivity factor. To normalize the voltage sensitivity factor, voltage sensitivity index as shown below is used:

$$
d V / d Q_{\text {Score } i}=\frac{d V / d Q_{i}-d V / d Q_{\min }}{d V / d Q_{\max }-d V / d Q_{\min }}
$$

Where

$d V / d Q_{i} \quad=$ voltage sensitivity at bus $i$

$d V / d Q_{\max }=$ maximum voltage sensitivity of the buses in the system

$d V / d Q_{\min }=$ minimum voltage sensitivity of the buses in the system

Using voltage sensitivity index, $d V / d Q_{\text {score }}$ will give the value between 0 and 1 . Bus with the score of 0 is bus with lowest voltage sensitivity factor in the system, while the score of 1 indicates bus with highest voltage sensitivity factor in power system.

\section{B.3. Angle Sensitivity Index}

To determine the placement of shunt reactors, shunt capacitors, and SVC, voltage index and voltage sensitivity index are enough. However, using the two indexes only is not sufficient to distinguish the placement of SVC and STATCOM. The placement of SVC and STATCOM needs to be considered because although STATCOM is generally better than SVC (faster response and better characteristic), STATCOM is more expensive than SVC. Therefore, angle sensitivity index is introduced to distinguish the placement of SVC and STATCOM to minimize the cost of FACTS devices. Using angle sensitivity index, SVC and STATCOM placement can be planned simultaneously.

Angle sensitivity index is obtained using load flow sensitivity analysis assuming $\Delta \mathrm{Q}=0$. Angle sensitivity index shows the influence of active power injection at buses that contribute to overall angle changes.

The use of angle sensitivity index to distinguish the placement of SVC and STATCOM could be explained by using rotor angle stability ( $\delta$-P curve) [17]. During fault, system voltage will drop. The closer a point to fault location, the closer voltage at that point is to zero. Shunt compensator can be used to raise the voltage, resulting smaller area A1. Smaller area A1 makes deviation of angle smaller, so that rotor angle stability improves.

Buses with high angle sensitivity are chosen as the location of STATCOM placement because they are more prone to rotor angle instability. By installing STATCOM that has faster response and better characteristic over SVC in the buses, rotor angle stability of system can be improved. The improvement in rotor angle stability can be shown by increase in critical clearing time. 


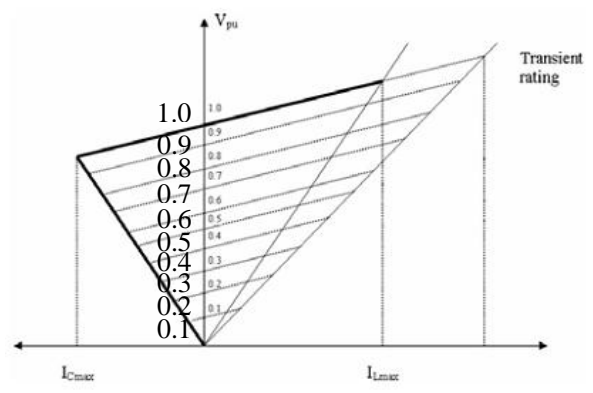

(a)

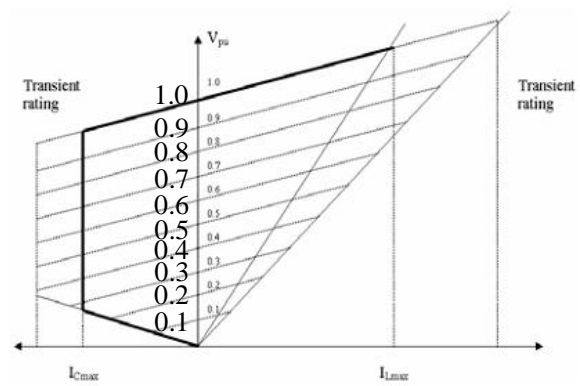

(b)

Figure 2. Characteristic of SVC (a) and STATCOM (b)

Every bus in power system has its unique angle sensitivity factor. To normalize the angle sensitivity factor, angle sensitivity index as shown below is used:

$$
d \delta / d P_{\text {Score } i}=\frac{d \delta / d P_{i}-d \delta / d P_{\min }}{d \delta / d P_{\max }-d \delta / d P_{\min }}
$$

Where

$d \delta / d P_{i} \quad=$ angle sensitivity at bus $i$

$d \delta / d P_{\max }=$ maximum angle sensitivity of the buses in the system

$d \delta / d P_{\min }=$ minimum angle sensitivity of the buses in the system

C. Bus Candidate Selection

C.1. General Bus Candidate

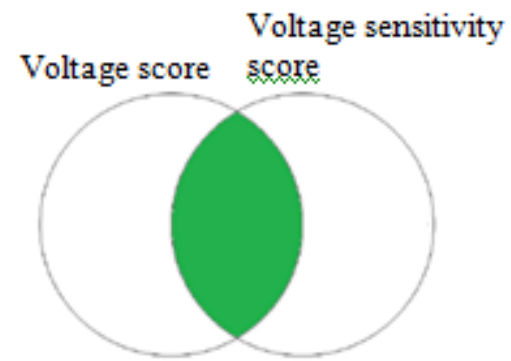

Figure 3. Bus candidates selection based on voltage score and voltage sensitivity score

General bus candidates for shunt VAR compensator placement are chosen based on voltage index and voltage sensitivity index. Buses with high voltage score and voltage sensitivity score 
are selected for shunt VAR compensator placement to solve voltage problems in the system. Illustration of the selection is shown in figure below. Each condition will have each bus candidate clusters. A cluster can intersect other cluster (Figure 3). Buses having high score only in peak load condition are candidates for shunt capacitor placement. While buses having high score only in low load condition are candidates for shunt reactor placement. In buses having high score in both peak load and low load condition, SVC or STATCOM can be used.

\section{C.2. SVC and STATCOM}

Bus candidates for SVC and STATCOM placement are chosen based on voltage index and voltage sensitivity index with the addition of angle sensitivity index. Illustration of selection is shown in Figure 4.

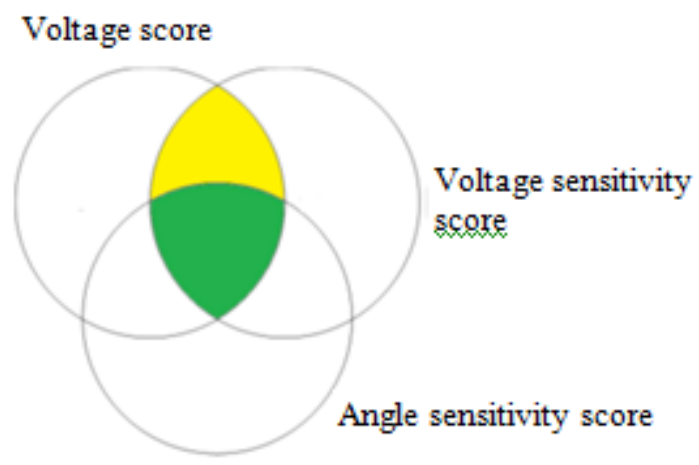

Figure 4. Selection of SVC and STATCOM: SVC (yellow) and STATCOM (green)

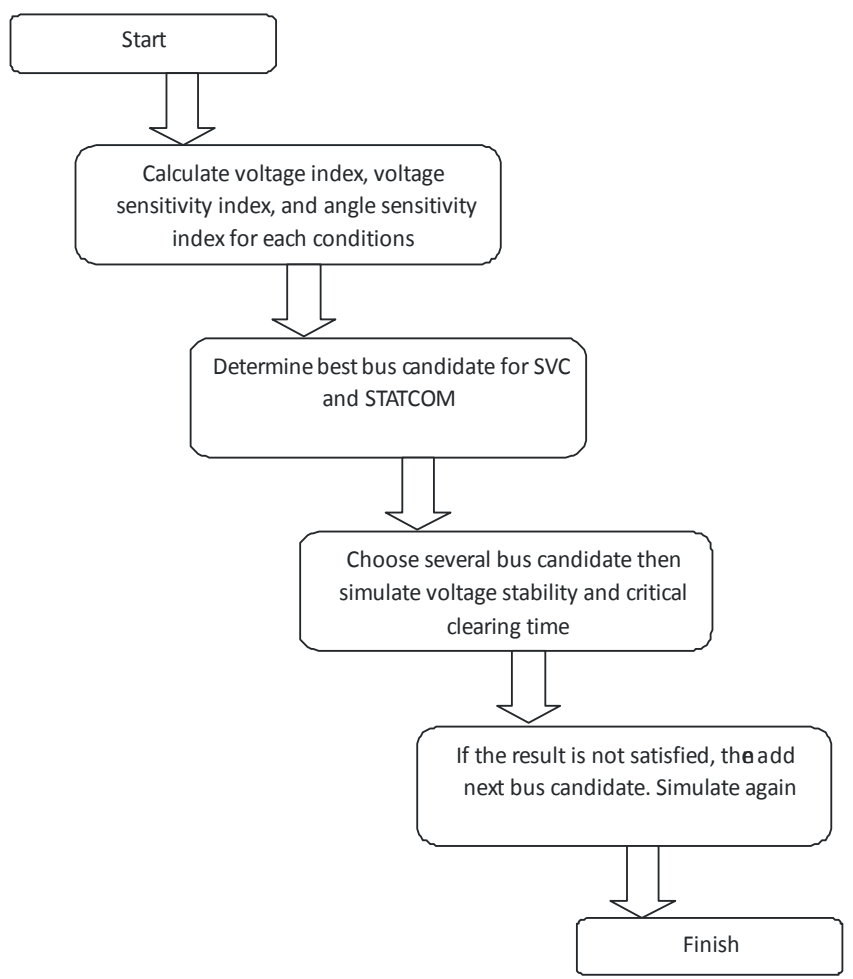

Figure 5. SVC and STATCOM placement algorithm 
STATCOM should be installed in buses having high voltage index, high voltage sensitivity index, and high angle sensitivity index, therefore STATCOM can be utilized optimally and economically.

The process to determine optimal location for shunt VAR compensator placement is illustrated by algorithm below.

\section{Results and Discussions}

In this work, only the selection of SVC and STATCOM placement is presented. The methods for choosing shunt capacitor, shunt reactor, and SVC based on sensitivity analysis are described in [18] and [19].

\section{A. 14-Generator SE Australian Power System}

14-generator test case is used to verify the proposed method. The data is obtained from [5]. In the test case, the use of SVC had been introduced. The default and proposed locations of SVC and STATCOM for the test case are shown in Table 1 while the impact to transient stability is shown in Table 2, represented by the critical clearing time (tcrit) of the CBs placed at the ends of the line.

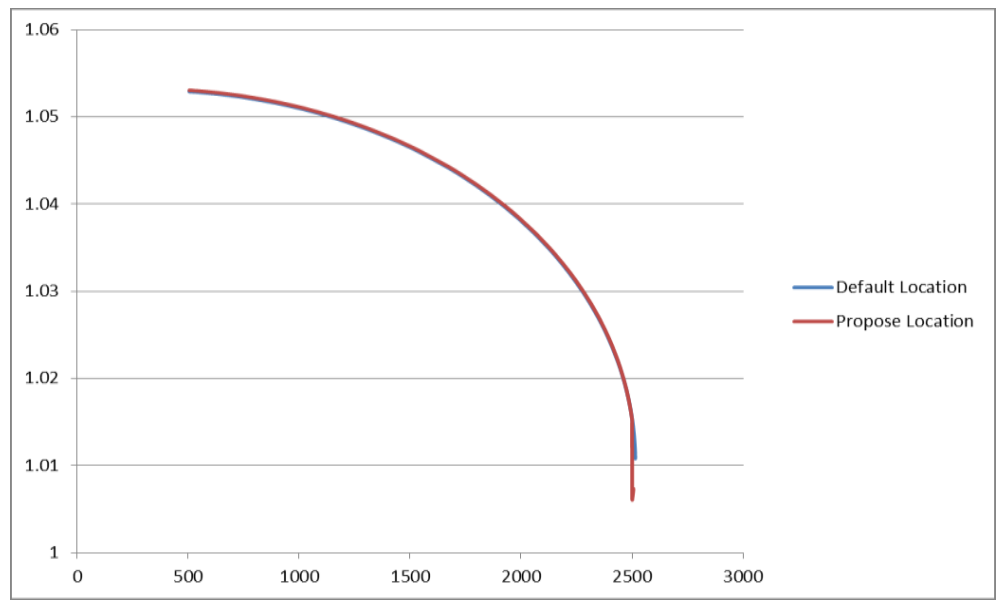

(a)

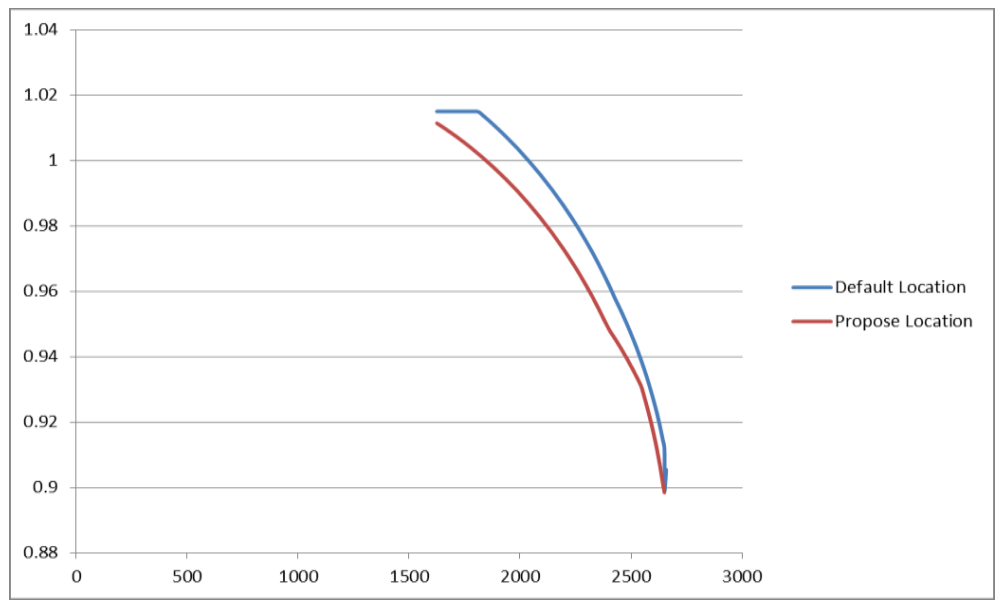

(b)

Figure 6. Voltage stability at bus 215 (a) and bus 313 (b) 
Voltage stability comparison between default and proposed location is shown in Figure 6. No significant difference in voltage stability is encountered when SVC and STATCOM is placed based on default placement and proposed method.

Table 1. Default and Proposed Location of SVC and STATCOM in 14-Generator Test Case

\begin{tabular}{|c|c|}
\hline Default Location & Proposed Location \\
\hline $205(\mathrm{SVC})$ & $205(\mathrm{SVC})$ \\
\hline $315(\mathrm{SVC})$ & $308(\mathrm{SVC})$ \\
\hline $412(\mathrm{SVC})$ & $406(\mathrm{STATCOM})$ \\
\hline $507(\mathrm{SVC})$ & $413(\mathrm{SVC})$ \\
\hline $509(\mathrm{SVC})$ & $509(\mathrm{SVC})$ \\
\hline
\end{tabular}

Rotor angle stability comparison between default and proposed location is shown in Table 2. Using the proposed location, rotor angle stability is increased, shown by the increase in critical clearing time.

Table 2 Critical Clearing Time Comparison between Default Placement and Proposed Placement in 14-Generator Test Case

\begin{tabular}{|l|l|}
\hline \multicolumn{1}{|c|}{ Default Location } & \multicolumn{1}{c|}{ Proposed Location } \\
\hline Line 315-509_1 tcrit $=0.211 \mathrm{~s}$ & Line $315-509 \_1$ tcrit $=0.258 \mathrm{~s}$ \\
\hline Line 102-217_2 tcrit $=0.273 \mathrm{~s}$ & Line 102-217_2 tcrit $=0.582 \mathrm{~s}$ \\
\hline Line 212-217 tcrit $=0.180 \mathrm{~s}$ & Line 212-217 tcrit $=0.312 \mathrm{~s}$ \\
\hline Line 209-212 tcrit $=0.126 \mathrm{~s}$ & Line $209-212$ tcrit $=0.188 \mathrm{~s}$ \\
\hline Line 208-211_1 tcrit $=0.118 \mathrm{~s}$ & Line 208-211_1 tcrit $=0.165 \mathrm{~s}$ \\
\hline Line 205-416_2 tcrit $=0.404 \mathrm{~s}$ & Line 205-416_2 tcrit $=1.000 \mathrm{~s}$ \\
\hline Line 408-410_1 tcrit $=0.126 \mathrm{~s}$ & Line 408-410_1 tcrit $=1.000 \mathrm{~s}$ \\
\hline Line 407-408 tcrit $=0.141 \mathrm{~s}$ & Line 407-408 tcrit $=0.497 \mathrm{~s}$ \\
\hline Line 410-412_1 tcrit $=0.141 \mathrm{~s}$ & Line 410-412_1 tcrit $=0.435 \mathrm{~s}$ \\
\hline Line 409-411_1 tcrit $=0.157 \mathrm{~s}$ & Line 409-411_1 tcrit $=1.000 \mathrm{~s}$ \\
\hline Line 405-408 tcrit $=0.134 \mathrm{~s}$ & Line 405-408 tcrit $=1.000 \mathrm{~s}$ \\
\hline Line 414-415_2 tcrit $=0.304 \mathrm{~s}$ & Line 414-415_2 tcrit $=1.000 \mathrm{~s}$ \\
\hline Line 504-507_1 tcrit $=0.296 \mathrm{~s}$ & Line 504-507_1 tcrit $=0.343 \mathrm{~s}$ \\
\hline
\end{tabular}

\section{B. Sumatera System}

By applying the proposed method on the test case, good results are obtained. Proposed method then applied to Sumatera power system in Indonesia in year 2013. To obtain the best candidate for almost every condition, the scores are calculated for several extreme conditions. In Indonesia, there are four extreme conditions:

- Peak load-wet season

- Peak load-dry season

- Low load-wet season

- Low load-dry season

On Figure 7, green area indicates bus candidates for every condition. Yellow areas represent bus candidates for three conditions, while buses included in blue area are bus candidates for two conditions. SVC or STATCOM are placed first on bus candidates that are included in green areas. If the improvement is not sufficient, SVC or STATCOM are placed on bus candidates in yellow and blue area respectively. 


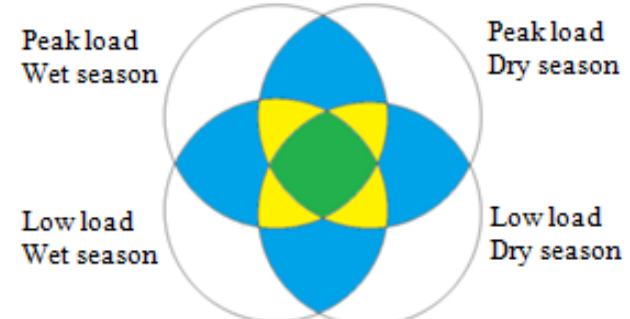

Figure 7. Bus candidates selection considering four different extreme operating conditions

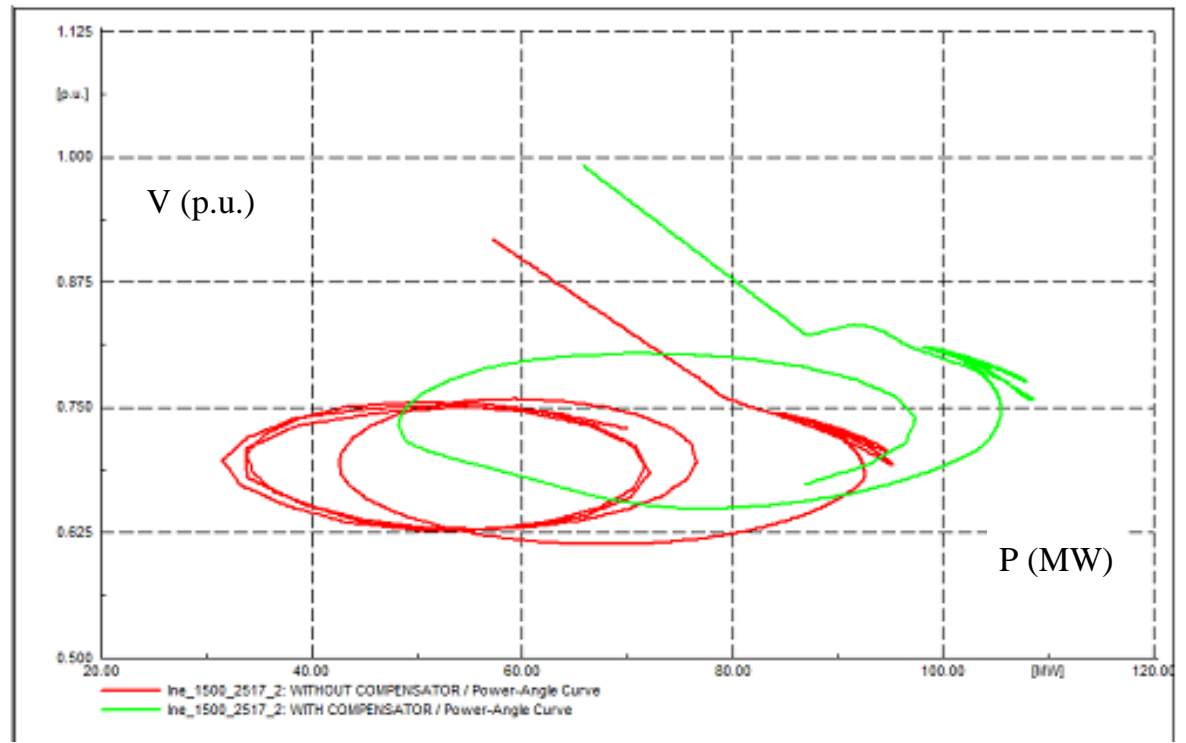

(a)

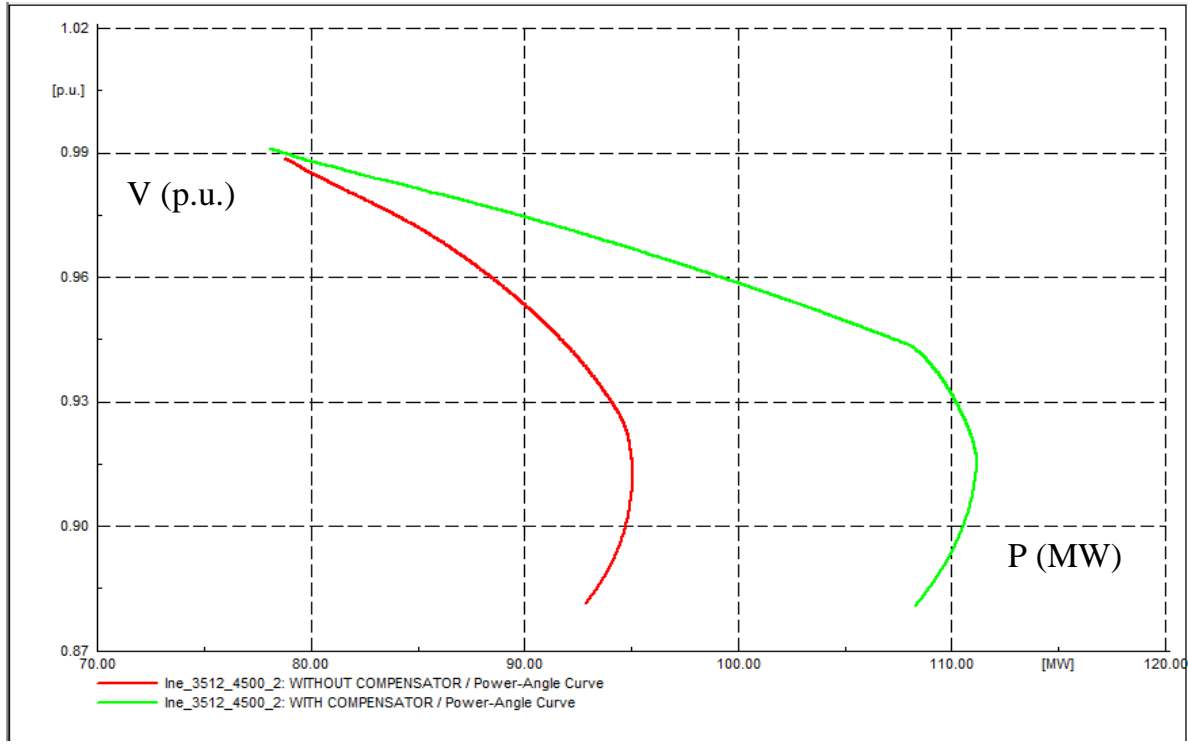

(b)

Figure 8. Maximum transfer based on voltage stability: from North Sumatera to Aceh (a) and from West Sumatera to Riau (b). Red curve indicates maximum transfer without compensator while green curves are the curves after compensators are installed 
Load and generation in each province is as shown in Table 3.

Table 3. Generation and Load in Sumatera Power System in 2013

\begin{tabular}{|l|c|c|}
\hline \multicolumn{1}{|c|}{ Province } & Generation $(M W)$ & Load $(M W)$ \\
\hline NAD & 194 & 324 \\
\hline North Sumatera & 1617 & 1422 \\
\hline Riau & 272 & 387 \\
\hline West Sumatera & 539 & 477 \\
\hline Jambi & 228 & 244 \\
\hline South Sumatera & 935 & 688 \\
\hline Bengkulu & 244 & 145 \\
\hline Lampung & 527 & 686 \\
\hline Total & 4556 & 4373 \\
\hline
\end{tabular}

Using load flow sensitivity and scoring result of the indexes, SVC and STATCOM locations are obtained as shown in Table 4. There are 4 SVCs and 2 STATCOMs needed to be installed in Sumatera system.

Table 4. SVC and STATCOM Locations for Sumatera Power System

\begin{tabular}{|l|c|c|}
\hline \multicolumn{1}{|c|}{ Substation } & Type & Size $($ L/C $)$ \\
\hline 7516 GWANG & SVC & $25 /-50 \mathrm{MVAR}$ \\
\hline 7553 MANNA & SVC & $15 /-30 \mathrm{MVAR}$ \\
\hline 1506 BACEH & STATCOM & $15 /-30 \mathrm{MVAR}$ \\
\hline 4506 BBATU & STATCOM & $15 /-30 \mathrm{MVAR}$ \\
\hline 1503 TLCUT & SVC & $25 /-50 \mathrm{MVAR}$ \\
\hline 1501 GIDIE & SVC & $25 /-50 \mathrm{MVAR}$ \\
\hline
\end{tabular}

Figure 8 shows that VAR compensator installation in Sumatera system could increase transfer capability of the tie lines. Improvement in maximum power transfer capability is achieved by inserting shunt VAR compensators into the system.

Table 5 shows rotor angle stability improvement. By installing shunt VAR compensators, critical clearing time of buses in the system increase, thus improving system stability.

Table 5. Critical Clearing Time Comparison of Several Lines in Sumatera Power System, With and Without Installment of Shunt VAR Compensator

\begin{tabular}{|c|c|c|c|c|c|c|c|c|}
\hline \multirow{4}{*}{ Lines } & \multicolumn{8}{|c|}{ Critical Clearing Time $(s)$} \\
\hline & \multicolumn{8}{|c|}{ Season } \\
\hline & \multicolumn{2}{|c|}{ Peak load-wet } & \multicolumn{2}{|c|}{ Peak load-dry } & \multicolumn{2}{|c|}{ Low load-wet } & \multicolumn{2}{|c|}{ Low load-dry } \\
\hline & $N C$ & $W C$ & $N C$ & $W C$ & $N C$ & $W C$ & $N C$ & $W C$ \\
\hline lne_1504_1502_1 & 0.585 & 0.585 & 0.599 & 0.697 & 0.430 & 0.507 & 0.261 & 0.346 \\
\hline lne_1504_1505_1 & 0.571 & 0.592 & 0.585 & 0.606 & 0.409 & 0.732 & 0.240 & 0.346 \\
\hline lne_1506_1505_1 & 0.592 & 0.606 & 0.606 & 0.627 & 0.669 & 0.978 & 0.247 & 0.388 \\
\hline lne_2535_2540_1 & 1.000 & 1.000 & 1.000 & 1.000 & 1.000 & 1.000 & 1.000 & 1.000 \\
\hline lne_4506_2540_1 & 1.000 & 1.000 & 1.000 & 1.000 & 1.000 & 1.000 & 1.000 & 1.000 \\
\hline lne_4502_4504_1 & 0.564 & 0.564 & 0.768 & 0.753 & 0.437 & 0.472 & 0.690 & 0.683 \\
\hline lne_4504_4506_2 & 0.901 & 0.895 & 1.000 & 1.000 & 1.000 & 1.000 & 1.000 & 1.000 \\
\hline lne_4504_4505_1 & 0.535 & 0.528 & 0.585 & 0.578 & 0.557 & 0.599 & 0.606 & 0.606 \\
\hline LNE 4504-4514 & 0.296 & 0.289 & 0.332 & 0.325 & 0.303 & 0.303 & 0.318 & 0.318 \\
\hline LNE 4514-4502 & 0.346 & 0.359 & 0.451 & 0.437 & 0.325 & 0.338 & 0.388 & 0.381 \\
\hline
\end{tabular}




\section{Conclusion}

- Installation of shunt reactive power compensation devices (SVC and STATCOM) increases total transfer capability by enhancing voltage stability and rotor angle stability.

- Using the proposed method, optimal locations and type of shunt reactive power compensation devices to be installed can be determined. The proposed method uses three indexes (voltage index, voltage sensitivity index, and angle sensitivity index) in choosing shunt VAR compensator's placement.

\section{References}

[1] Prabha Kundur, Power System Stability and Control. United States of America: McGrawHill, Inc., 1994.

[2] Taylor Carson W., Power System Voltage Stability.: McGraw-Hill, Inc., 1994.

[3] US-Canada Power System Outage Task Force, "Final Report on the August 14, 2003 Blackout in the United States and Canada: Causes and Recommendation,".

[4] Wenjuan Zhang, Fangxing Li, and Leon M. Tolbert. Optimal Allocation of Shunt Dynamic Var Source SVC and STATCOM: A Survey. [Online]. http://web.eecs.utk.edu/ tolbert/publications/apscom_2006.pdf

[5] Mike Gibbard \& David Vowles, "SIMPLIFIED 14-GENERATOR MODEL OF THE SE AUSTRALIAN POWER SYSTEM," The University of Adelaide, South Australia, 2010.

[6] S. C. Srivastava M. K. Verma, "Optimal placement of SVC for static and dynamic voltage security enhancement," International Journal of Emerging Electric Power System, vol. 2, no. 2, 2005.

[7] W. Xu, F. Alvarado, and C. Rinzin Y. Masnsour, "SVC Placement Using Critical Modes of Voltage Instability," IEEE Trans. on Power System, vol. 9, no. 2, pp. 757-763, May 1994.

[8] W. W. Ping, A. R. Carvalho, A. Wey, W. F. Long, C. L. L. A. S. Pilotto, "Determination of needed FACTS controllers that increase asset utilization of power system," IEEE Transactions on Power Delivery, vol. 12, no. 1, pp. 3633-371, January 1997.

[9] A. R. Messina, C. R. Fuerte-Esquivel M. A. Perez, "Application of FATCS devices to improve steady state voltage stability," 2000 IEEE Power Engineering Society Summer Meeting, vol. 2, pp. 1115-1120, July 2000.

[10] K. Madajewski, M. Sobierajski R. Adapa, "The Study of Voltage Problems in Polish Power System," 2002 IEEE International Conference on Industrial Technology, vol. 3, pp. 285-290, December 2002.

[11] P. Preedavichit and S. C. Srivastava, "Optimal reactive power dispatch considering FACTS devices," in Proceedings of the 4th International Conference on Advances in Power System Control, Operation and Management, APSCOM-97, Hongkong, November 1997, pp. 620-625.

[12] W. Ongsakul P. Bhasaputra, "Optimal power flow with multi-type of FATCS devices by hybrid TS/SA approach," 2002 IEEE International Conference on Industrial Technology, vol. 1, pp. 285-290, December 2002.

[13] G. Radman R. Natesan, "Effects of STATCOM, SSSC and UPFC on voltage stability," in 2004 Proceedings of the Thirty-Sixth Southeastern Symposium on System Theory, 2004, pp. 546-550.

[14] T. Shimato, M. Tsukada, K. Matsuno, I. Iyoda, J. J. Paserba, G. F. Reed H. Yonezawa, "Study of a STATCOM application for voltage stability evaluated by dynamic PV curves and time simulation," 2000 IEEE Power Engineering Society Winter Meeting, vol. 2, no. 1471-1476, January 2000.

[15] G. Pampin, J. D. de Leon H. G. Sarmiento, "FACTS solutions for voltage stability 
problems in a large metropolitan area," 2004 IEEE/PES Power Systems Conference and Exposition, vol. 1, pp. 275-282, October 2004.

[16] B. Gao, P. Kundur G. K. Morison, "Voltage stability analysis using static and dynamic approaches," IEEE Transactions on Power System, vol. 8, no. 3, pp. 1159-1171, August 1993.

[17] John J. Granger and William D. Stevenson, Power System Analysis.: McGraw-Hill, Inc., 1994.

[18] Dimas Adi Nugraha, "Penentuan Lokasi Peletakan Kompensator Daya Reaktif Sebagai Usaha Perbaikan Tegangan Pada Sistem Transmisi Sumatera 2011," Institut Teknologi Bandung, Bandung, 2011.

[19] Adhi Eko Apriyanto, "Penentuan Lokasi Peletakan Kompensator Daya Reaktif Sebagai Usaha Perbaikan Tegangan Pada Sistem Transmisi Jawa Bali 2013," Institut Teknologi Bandung, 2013.
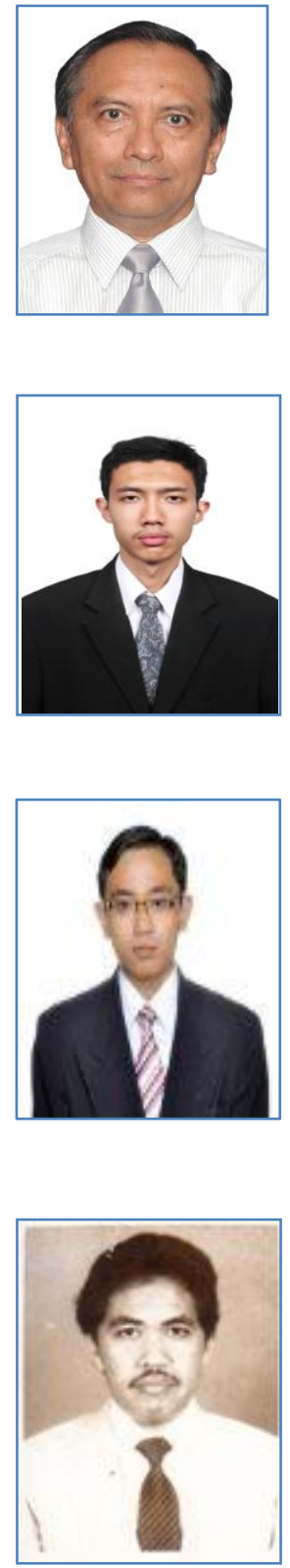

Muhammad Nurdin received his Sarjana (Bachelor) degree in Electrical Engineering from Institut Teknologi Bandung (ITB), Indonesia in 1978, and his DEA and Doctoral degrees in Electrical Power Engineering from Institut National Polytechnique de Grenoble, France in 1985 and 1988 respectively. He is currently working as lecturer in the School of Electrical Engineering and Informatics ITB.

Fathin Saifur Rahman is a research assistant in School of Electrical Engineering and Informatics at Institut Teknologi Bandung. He received his B.Sc in Electrical Power Engineering from Institut Teknologi Bandung in 2012 and received his M.Sc in Electrical Engineering in 2013 from same university. His research interests are in applications of synchrophasor in power system and also in the areas of smart grid and clean energy.

Rizky Rahmani received his B.Sc in Electrical Power Engineering from Institut Teknologi Bandung in 2011 and received his M.Sc in Electrical Engineering in 2014 from same university. His research interests are in applications of synchrophasor in power system and system stability.

Nanang Hariyanto was born in Jember, Jawa Timur, Indonesia, on July 26, 1962. He graduated from the Electrical Engineering Department, Bandung Institute of Technology. His employment experience included Synatech Industry, and as a researcher at Power System Laboratory, ITB Indonesia. His special fields of interest included power system planning and dynamic stability. 